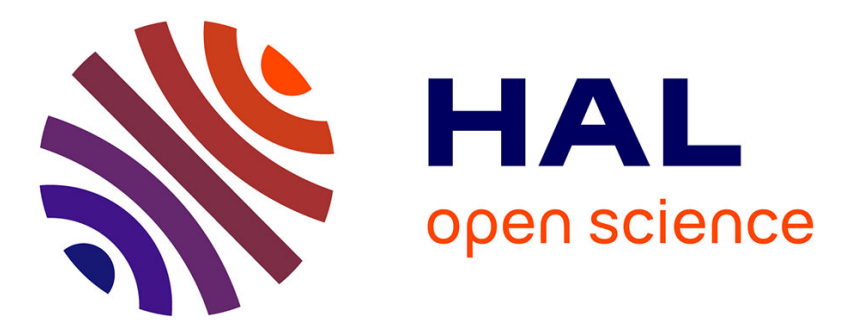

\title{
Surface and microstructure modifications of Ti-6Al-4V titanium alloy cutting by a water jet/high power laser converging coupling
}

\author{
Laurent Weiss, Abdel Tazibt, Michel Aillerie, Albert Tidu
}

\section{To cite this version:}

Laurent Weiss, Abdel Tazibt, Michel Aillerie, Albert Tidu. Surface and microstructure modifications of Ti-6Al-4V titanium alloy cutting by a water jet/high power laser converging coupling. Materials Research Express, 2018, 5 (1), pp.016528. 10.1088/2053-1591/aaa827 . hal-02005182

\section{HAL Id: hal-02005182 \\ https://hal.science/hal-02005182}

Submitted on 25 Jan 2020

HAL is a multi-disciplinary open access archive for the deposit and dissemination of scientific research documents, whether they are published or not. The documents may come from teaching and research institutions in France or abroad, or from public or private research centers.
L'archive ouverte pluridisciplinaire HAL, est destinée au dépôt et à la diffusion de documents scientifiques de niveau recherche, publiés ou non, émanant des établissements d'enseignement et de recherche français ou étrangers, des laboratoires publics ou privés. 
Surface and microstructure modifications of Ti-6Al-4V titanium alloy cutting by a water jet/high power laser converging coupling 


\title{
Surface and microstructure modifications of Ti-6Al-4V titanium alloy cutting by a water jet/high power laser converging coupling
}

\author{
Laurent WEISS ${ }^{1}$, Abdel TAZIBT $^{2}$, Michel AILLERIE $^{3,4}$ and Albert TIDU ${ }^{1}$ \\ ${ }^{1}$ Laboratoire d'Etude des Microstructures et Mécanique des Matériaux, UMR CNRS 7239, Université de \\ Lorraine, 7 rue Félix Savart, Metz, France \\ ${ }^{2}$ Centre de Recherche, d'Innovation et de Transfert Technologique en Jet Fluide, 2 Avenue de la Grande Terre \\ 55000 Bar-le-Duc, France \\ ${ }^{3}$ Laboratoire Matériaux Optiques, Photonique et Systèmes, EA 4423, Université de Lorraine, 2 rue Edouard \\ Belin, Metz, France \\ ${ }^{4}$ Laboratoire Matériaux Optiques, Photonique et Systèmes, CentraleSupelec, 2 rue Edouard Belin, Metz, France
}

\begin{abstract}
The metallurgical evolution of the Ti-6Al-4V samples is analyzed after an appropriate cutting using a converging water jet/high power laser system. New surface microstructures are obtained on the cutting edge as a result of thermo-mechanical effects of such hybrid fluid-jetlaser tool on the targeted material. The laser beam allows to melt and the water-jet to cool down and to evacuate the material upstream according to a controlled cutting process. The experimental results have shown that a rutile layer can be generated on the surface near the cutting zone. The recorded metallurgical effect is attributed to the chemical reaction between water molecules and titanium, where the laser thermal energy brought onto the surface plays the role of reaction activator. The width of the oxidized zone was found proportional to the cutting speed. During the reaction, hydrogen gas $\mathrm{H}_{2}$ is formed and is absorbed by the metal. The hydrogen atoms trapped into the alloy change the metastable phase formation developing pure $\beta$ circular grains as a skin at the kerf surface. This result is original so it would lead to innovative converging laser water jet process that could be used to increase the material properties especially for surface treatment, a key value of surface engineering and manufacturing chains.
\end{abstract}




\section{Subject-matter keywords}

Ti-6Al-4V Cutting, surface treatment, Laser Water Jet coupling, Oxide formation, metallurgy

\section{Introduction}

For more than one decade, a lot of publications proposed the study of laser/material interactions in an aqueous environment using different processes that can be separated in three groups. The first one gathers the processes where a laser hits targets completely immersed in water pool. Among these studies, we can highlight the works of Sakka et al [1] about graphite, the works of Shafeev and Simakhin [2] about silicon and the works of Alfille et al [3] about steel. The second group gathers the processes where the sample is immersed in a controlled gaseous atmosphere where a laser hits the material surface along with either water or steam jet that targeting simultaneously the area to be cut in order either to cool down the material or to activate chemical reaction as in the work done by Geiger et al [4]. The last group gathers different type of exotic interactions such as fluidic optical fiber on copper, as presented by Porter et al [5], or silicon presented by Kray et al [6], or the works done by Dupont et al using waterfall on the material surface [7] or the one made by Matsumoto et al in a fluid/air mix [8]. For more detailed informations, Kruusing [9-10] has published a very complete and detailed review of all these techniques. However, all these studies focus on the physical phenomena such as vapor bubbles formation, colloid formation, cracks and surface activation.

Few studies addressed metal cutting and, to our knowledge, none of them deals with titanium alloys reactions and transformations when using a laser/water jet mixture. Fluidic optical fiber cutting, which has existed for around 15 years, allows cutting of thin materials (100 microns) due to the usage of only low laser power and static water pressure (100 W, $10 \mathrm{MPa})$. Engineers are currently working to increase the power of such hybrid system allowing the possibility of cutting thick sheets while limiting the Heat Affected Zone (HAZ), thus 
presenting a huge interest in many applicative sectors as those concerned in aeronautic industry.

Due to this high applicative potential, in a previous paper, we have presented experimental results and interpretations of the structural changes and phase transformations during cutting of stainless steel with a coupled Laser Water Jet (LWJ) converging on the surface [11]. Using a $400 \mathrm{~W}$ laser, we have shown by different characterization techniques that due to the deposited energy, the reactivity of water molecules with the surface greatly increases, creating an exotic oxidation of the material.

In order to analyze new possibilities of this hybrid laser-water jet cutting process, and deeper consider interactions and new physical effects and properties that we can expect with this technique on other metallic materials, we specially focused on titanium alloys and more specifically on Ti-6Al-4V. This alloy is one of the most common alloy used in aeronautic industry applications because of its lightness, corrosion resistance and mechanical properties. But it is well known that this alloy is subject to phase transformation during quenching. When it is cooled down from high temperature, the body centered cubic (BCC) $\beta$ phase is transformed into martensite $\alpha^{\prime}$. As we will show in this paper, our investigations have allowed us to oversee the formation of exotic microstructures never seen before in this alloy due to the very fast heat and cooling associated process. The obtained original results further demonstrate and confirm the ability of this process to be used not only in cutting but also as tool for surface treatment of a wide variety of metallic alloys.

\section{Experimental setup}

The principle of the test is shown Fig.1. Excepted for the cutting speed now varying from 5 to $20 \mathrm{~mm} / \mathrm{min}$ rated in steps of $1 \mathrm{~m} / \mathrm{min}$, the experimental parameters, instruments and machines are the same as those of our previous works, here being summarized, i.e. a Yb:YAG laser 
(wavelength $=1030 \mathrm{~nm}$, spot size $=113 \mu \mathrm{m}$, power $=400 \mathrm{~W}$ ) ; water pumped at $1 \mathrm{MPa}$ through a $0.25 \mathrm{~mm}$ nozzle diameter [11]. The optimal cutting speed with small-oxidized zone and net shape quality cut is found to be equal to $11 \mathrm{~m} / \mathrm{min}$. This optimal cutting speed leads to minimum streaks.

\section{Figure 1}

The characterization of the transformation at the surface (oxide layer formation) was performed with two different techniques. The first one is the X-Ray Diffraction (XRD) with a diffractometer MFDP equipped with a curved position sensitive detector CPS 120 (INEL) and a copper anode $\left(\mathrm{K}_{\alpha}=0,154018 \mathrm{~nm}\right)$. The other characteristics of the X-Ray diffractometer are $0.027^{\circ}(2 \theta)$ acquisition step with an acquisition time equal to $2 \mathrm{~s}$, at $40 \mathrm{kV}$ tension and 200 $\mathrm{mA}$ intensity collimated at $0.6 \mathrm{~mm}$.

The Raman spectrometer is a LabRam Aramis working with an excitation beam at $532 \mathrm{~nm}$ focuses with an objective x20 and the Scanning Electron Microscope is a Carl Zeiss model 40. These apparatus and associated parameters are the same as those of our previous work [11]. The samples were prepared using an etching with Kroll's reagent consisting of $2 \mathrm{ml}$ of fluoridric acid, $3 \mathrm{ml}$ of nitric acid and $95 \mathrm{ml}$ of water.

The resulting cutting residues are pulled away by the jet and recovered after being filtered and separated into liquid effluent and powders. The obtained dry powder material is then analyzed.

\section{Experimental results and discussion}

During the cutting process, a first stage before cutting being effective, leads to the formation of an initial crater followed by gas and material ejection. In the same time, the adjacent 
material of the cutting zone is rapidly heated and quenched, leading to the formation of a nonequilibrium temperature field propagating into the bulk. As a first result, we notice the formation of oxide on the surface of the two wall sides of the kerf, as shown in Figure 2.

\section{Figure 2}

The width of the oxidized zone ranges from 0.6 to $1.7 \mathrm{~mm}$ depending on the cutting speed. The $11 \mathrm{~m} / \mathrm{min}$ cutting speed has been found to be the best relationship between size of the oxidized zone and rough edge. Higher is the cutting speed, higher will be the roughness and, at the opposite, lower it is, higher will be the oxidized area. This influence is shown in Figure 3.

\section{Figure 3}

The linear decrease of the width of the oxidized zone with the cutting speed can be explained as follows: the laser brings in enough energy to activate the oxidation reaction, leading to the growth of the oxide layer. One can argue that lesser is the cutting speed, higher will be both the thermal diffusion inside the material and the expansion of hot reactive zone between titanium and water.

A study of Boivineau [12] explains that at room temperature, the Ti-6Al-4V is a two-phase $\alpha$ $+\beta$ alloy with a small percentage (between 6 and $8 \%$ ) of $\beta$-phase. The $\alpha$ and $\beta$ phases have two different crystallographic structures: body centered cubic for the $\beta$ phase and hexagonal compact for the $\alpha$ phase. The morphology of the $\alpha$ phase can be either globular, lamellar or acicular as function of the heat treatment. This last one prevails when the alloy has been 
solution in $\beta$ phase then cooled. During heating and in conditions of equilibrium, there is a dissolution of the $\alpha$ phase and the $\beta$ phase content increases to be equal to 1 at temperatures above the normal phase transus temperature $\mathrm{T}_{\beta}$ equal to $1000^{\circ} \mathrm{C}$ (for $\mathrm{Ti}-6 \mathrm{Al}-4 \mathrm{~V}$ ) as mentioned by Tamirisakandala et al [13]. For very high cooling rate from the $\beta$ domain, the alloy undergoes a martensitic transformation $\beta \rightarrow \alpha^{\prime}$. The martensitic phase has the same chemical composition as the $\beta$ phase and its crystal structure is hexagonal-close-packed, HCP phase.

As confirmed by XRD analysis in the figure 4, before being cut, the Ti- $6 \mathrm{Al}-4 \mathrm{~V}$ possesses a two-phase $\alpha+\beta$ microstructure. After cutting, we can observe a residue of martensitic phase. XRD patterns, measured using integrated $\phi-\Psi$ measurements, have showed that the peaks of the $\beta$ and martensite do not vary, meaning that the material is isotropic i.e. without specific crystallographic orientation.

The first step to determine the nature of the created oxide is the analysis of the X-Ray diffractograms recorded at the material surface near the cutting edge. On the Figure 4, we note the appearance of rutile $\left(\mathrm{TiO}_{2}\right)$ diffraction peaks corresponding, for the first three peaks, to the (110), (101) and (211) diffracting planes as reported by Ding et al. [14] and Hu et al. [15]. Surprisingly, no martensite peak is visible. This result will be discussed further in this paper.

\section{Figure 4}

Figure 5 shows the Raman spectra obtained for the Ti-6Al-4V raw material, the oxidized zone and for the cutting residues powder. On this spectra, the first remarkable observation is the disappearance of the amorphous carbon peaks after cutting. This carbon represents the various 
organic compounds involved on the surface of the material (deposition, oil, organic material ...) and is washed away because of the water and the heat.

Moreover, the spectra obtained by Raman spectroscopy confirm the results of XRD and show the presence of rutile in both the oxidized zone and the cutting residues, respectively with the peaks at 238, 440 and $607 \mathrm{~cm}^{-1}$, which corresponds to the positions of peaks associated to the rutile according to Swamy [16] and Samuel et al [17]. We can deduce that the hybrid cutting process creates a titanium oxide layer. This also confirms that the cutting of Ti-6Al-4V induces the same oxidation process as in steel cutting [11] but with a different chemical reaction.

\section{Figure 5}

Jaroenworaluck et al [18] has described the formation of rutile on titanium in presence of water. The laser heats the Ti-6Al-4V surface, and a part of this heat is transferred to the water transformed into vapor. This last is very reactive with the titanium and forms a layer of rutile by oxidation of metal. By this way, the water will react with the titanium following the oxidation reaction:

$$
\mathrm{Ti}+2 \mathrm{H}_{2} \mathrm{O}_{(\mathrm{g})} \leftrightarrow \mathrm{TiO}_{2}+2 \mathrm{H}_{2(\mathrm{~g})}
$$

Wouters et al [19] have shown that the oxidation reaction, Eq. 1, of titanium to rutile is much faster in water than in air and energy required for the reaction is lower. The rutile is chemically very stable, so afterwards, there is no reaction with water and no by-product formed. Although the oxidation of titanium in the air also creates oxynitrides, they have not been detected because the sample always remains in an aqueous medium during the process without any contact with the ambient air.

Dihydrogen formed throughout the oxidation reaction will have a major influence on the microstructure observed at the cutting edge (Figure 6). Surprisingly, the obtained groove 
surface is constituted of a fine grain equiaxed beta skin while normally, after quenching, Ti$6 \mathrm{Al}-4 \mathrm{~V}$ is formed of fine needles of martensite $\alpha^{\prime}$ as indicated by the Sieniawski's CCT diagram of Ti-6Al-4V [20]. To our knowledge, this main effect has never been detected before and thus is originally considered here and explained in a relatively simple way with the hydrogen effect.

\section{Figure 6}

At the convergence impact point of laser beam and water jet with the material, the metal spend during a very short time into liquid state and then is ejected from the kerf and cooled down simultaneously by the water jet. During this time, the dihydrogen diffuses into the titanium and very quickly into the $\beta$ phase. The diffusion coefficients were given by Sundaram et al for the $\alpha$ phase [21] and by Christ et al for the beta phase [22]. Their values for the diffusion in the cell are $D_{\alpha}=2.6 \times 10^{-10} \mathrm{~cm}^{2} \cdot \mathrm{s}^{-1}$ and $D_{\beta}=1.1 \times 10^{-4} \mathrm{~cm}^{2} \cdot \mathrm{s}^{-1}$ so the diffusion is very high in the $\beta$ phase compared to the $\alpha$ one. Froes et al [23] have shown the importance of hydrogen influence on the titanium phase stability and formation. It is a powerful $\beta$ stabilizing alloying element and decreases the beta transus temperature until $300^{\circ} \mathrm{C}$ in the Ti-H phase diagram. Moreover, it changes significantly the kinetic of metastable phase formation during quenching. To resume, hydrogen diffuses into the matrix until $5 \mu \mathrm{m}$ depth (Figure 6a) and changes the phase formation kinetic to stabilize $\beta$ phase after quenching (Fig 6b).

It is therefore possible to set that there is a zone wherein pure beta phase may exist (or may be formed) at room temperature when this alloy is heated and then cooled very quickly with the presence of hydrogen. The Figure 7 illustrates the $\beta$ domain with the red curve and the fast cooling created by the Laser Water Jet with the blue curve. 


\section{Figure 7}

The stability of the beta phase is particularly important as aluminium, the $\alpha$ stabilising alloying element evaporates under the effect of the laser. This effect is clearly visible in Figure 8 wherein the aluminium percentage decreases rapidly as it approaches the cutting edge. Indeed, Robert [24] has noted that, during the formation of the keyhole in laser welding, the ionized vapors, generated by the laser, cause the vaporization of aluminum (vaporization temperature of aluminum is $2792^{\circ} \mathrm{K}$, vanadium $3682^{\circ} \mathrm{K}$ and titanium $3633^{\circ} \mathrm{K}$ ). The loss of aluminum, especially as the gain of hydrogen is high, greatly favors the $\beta$ phase stability.

\section{Figure 8}

Finally, Fig.6a and Fig.6c highlight an additional information resulting of this hybrid process impact on surface of titanium alloys. It addresses the microstructure under the $\beta$ layer of skin. It is found that this microstructure can be divided into two sub-layers. In the first one $(40 \mu \mathrm{m}$ long), close to the $\beta$ skin, we can observe primary $\alpha_{\mathrm{p}}$ phase with very big distorted grains. Both phase and shape are consequences of thermo-mechanical effect during quenching. In fact, even if the cooling is very fast, it exists a shorter initial period of time when the pasty metal is compressed by the water jet impact. This mechanical effect may prevent the formation of martensite and promotes $\alpha_{\mathrm{p}}$ phase recrystallization as explain by Combres [25]. The second sub-layer is constituted by small and equiaxe $\alpha_{\mathrm{p}}$ grains due to the low temperature (thermal effect) and dynamic pressure (mechanical effect), both recorded on the material to be cut. Any particular orientation or texture may appear in those sub-layers. Then, under the sublayers, the material becomes classic again with a small HAZ and where the temperature is higher than the $\beta$ transus and lower than the melting point. 


\section{Conclusion}

Using a hybrid Laser-Water Jet converging cutting system in particular processing conditions, we have originally demonstrated and studied the formation of rutile around the kerf performed in a Ti-6Al-4V alloy. The linear evolution of the oxide width as function of the feed rate due to the thermal diffusion coupled to mechanical effect has been measured. The resulting chemical reaction produces hydrogen that diffuses into the molten material. This interstitial hydrogen leads the stabilization of $\beta$ phase after quenching. This means that with this technique, it becomes possible and easy to form $\beta$ skin at the surface of titanium $\alpha+\beta$ alloy so as to increase the surface properties, like adsorption and absorption, to optimize them for specific applications. Furthermore, we have proved with the $\alpha_{\mathrm{p}}$ formation that a hybrid laser water jet presents a thermo-mechanical effect during the cutting process potentially interesting for applications of titanium alloys having cuts requiring a small heat activation zone.

The success of this innovative technology into the formation of novel phases in materials is challenging as it encourage its use in the future on many other metals to supplement knowledge on phases formation in extreme conditions.

\section{Acknowledgment}

This study is supported by the ADEME, GIP 55 and Europe FEDER.

\section{References}

[1] T. Sakka, S. Iwanaga and Y.H. Ogata, Laser ablation at solid-liquid interfaces: an approach from optical emission spectra, Journal of Chemical Physics, vol.112, n 19 , p.86458653 (2000)

[2] G.A Shafeev and A.V Simakhin, Spatially confined laser-induced damage of Si under a liquid layer, Applied Physics A, vol.54, p.311-316 (1992) 
[3] J.P. Alfille, G. Pilot, D. de Prunelle, New pulsed YAG laser performances in cutting thick metallic materials for nuclear applications, Proceeding SPIE, p.134-144 (1996)

[4] M. Geiger, W. Becker, T. Rebhan, J. Hutfless and N. Lutz, Increase of efficiency for the XeCl excimer laser ablation of ceramics, Applied Surface Science, vol.96, p.301-315 (1996)

[5] J. Porter, Y.A. Louhisalmi, J.A. Karjalainen and S. Füger, Cutting thin sheet metal with a water jet guided laser using various cutting distances, feed speeds and angles of incidence, The International Journal of Advanced Manufacturing Technology, vol.33, issue 9-10, pp 961-967 (2007)

[6] D. Kray, S. Hopman, A. Spiegel, B. Richerzhagen and G.P. Willeke, Study on the edge isolation of industrial silicon solar cells with waterjet-guided laser, Solar Energy Materials and Solar Cells, vol.91, pp.1638-1644 (2007)

[7] A. Dupont, P. Caminat and P. Bournot, Enhancement of material ablation using 248, 308, 532, $1064 \mathrm{~nm}$ laser pulse with a water film on the treated surface, Journal of Applied Physics, vol.78, p.2022-2028 (1995)

[8] O. Matsumoto, M. Sugihar, K. Miya, Underwater cutting of reactor core internals by CO laser using local-dry-zone creating nozzle, Journal of Nuclear Science and Technology, vol.29, issue 11, p.1074-1079 (1992)

[9] A. Kruusing, Underwater and water-assisted laser processing: Part 1-general features, steam cleaning and shock processing, Optics and Lasers in Engineering 41, p.307-327 (2004) [10] A. Kruusing, Underwater and water-assisted laser processing: Part 2-Etching, cutting and rarely used methods, Optics and Lasers in Engineering 41, p.329-352 (2004)

[11] L. Weiss, M. Aillerie, A. Tazibt and A. Tidu, Surface oxidation and phase transformation of the stainless steel by hybrid laser-waterjet impact, Materials Research Express, vol. 1, 036501 p.1-12 (2014)

[12] M. Boivineau, C. Cagran, D. Doytier, V. Eyraud, M.H. Nadal, B. Wilthan and G. Pottlacher, Thermophysical Properties of Solid and Liquid Ti-6Al-4V (TA6V) Alloy, International Journal of Thermophysics, vol.27, $\mathrm{n}^{\circ} .2$, p.507-529 (2006)

[13] S. Tamirisakandala, R.B. Bhat, D.B. Miracle, S. Boddapati, R. Bordia, R. Vanover, and V.K. Vasudevan, Effect of boron on the beta transus of Ti-6Al-4V alloy, Scripta Materialia, vol. 53, p.217-222 (2005)

[14] X. Z. Ding, X. H. Liu and Y.Z. He, Grain size dependence of anatase-to-rutile structural transformation in gel-derived nanocrystalline titania powders, Journal of Materials Science Letters, Vol.15, p.1789-1791(1996) 
[15] Y. Hu, H.L. Tsai, C.L. Huang, Effect of brookite phase on the anatase-rutile transition in titania nanoparticules, Journal of the European Ceramic Society, Vol.23, p.691-696 (2003) [16] V. Swamy, Size-dependent modifications of the first-order Raman spectra of nanostructured rutile $\mathrm{TiO}_{2}$, Physical Review B, Vol.77, 195414, p.1-4 (2008)

[17] V. Samuel, R. Pasricha, V. Ravi, Synthesis of nanocrystalline rutile, Ceramics International, Vol.31, p.555-557 (2005)

[18] A. Jaroenworaluck et al, Macro, micro and nanostructure of TiO2 anodised films prepared in a fluorine-containing electrolyte, Journal of Material Science, Vol.42, p.67296734 (2007)

[19] Y. Wouters, A. Galerie and J.P. Petit, Thermal oxidation of titanium by water vapour, Solid State Ionics, Vol.104, p.89-96 (1997)

[20] J. Sieniawski, W. Ziaja, K. Kubiak and M. Motyka, Microstructure and Mechanical Properties of High Strength Two-Phase Titanium Alloys, Titanium Alloys - Advances in Properties Control, book edited by Jan Sieniawski and Waldemar Ziaja, ISBN 978-953-511110-8, chap. 4, p.69-80 (2013)

[21] P.A. Sundaram E. Wessel, H. Clemens, H. Kestler, P.J. Ennis, W.J. Quadakkers, and L. Singheiser, Determination of the diffusion coefficient of hydrogen in gamma titanium aluminides during electrolytic charging, Acta materialia, Vol.48, p. 1005-1019 (2000)

[22] H.-J. Christ, M. Decker and S. Zeitler, Hydrogen Diffusion Coefficients in the Titanium Alloys IMI 834, Ti 10-2-3, Ti 21 S, and Alloy C, Metallurgical and Materials Transactions A, Vol.31A, p.1507-1517 (2000)

[23] F.H. Froes, O.N. Senkov and J.I. Qazi, Hydrogen as a tempory alloying element in titanium alloys: thermohydrogen processing, International materials Review, Vol.49, n³-4, p.227-245 (2004)

[24] Y. Robert, Simulation numérique du soudage du TA6V par laser YAG impulsionnel : caractérisation expérimentale et modélisation des aspects thermomécaniques associées à ce procédé (in french), $\mathrm{PhD}$ Thesis, Centre des Materiaux P.M. Fourt, Mines ParisTech (ENSMP), France, p.63 (2007)

[25] Y. Combres, Propriétés du titane et de ses alliages (in french), Techniques de l'Ingénieur, m557, p.1-15 (1999) 
Fig.1 : Schematic principle of the cutting system using converging water jet laser process

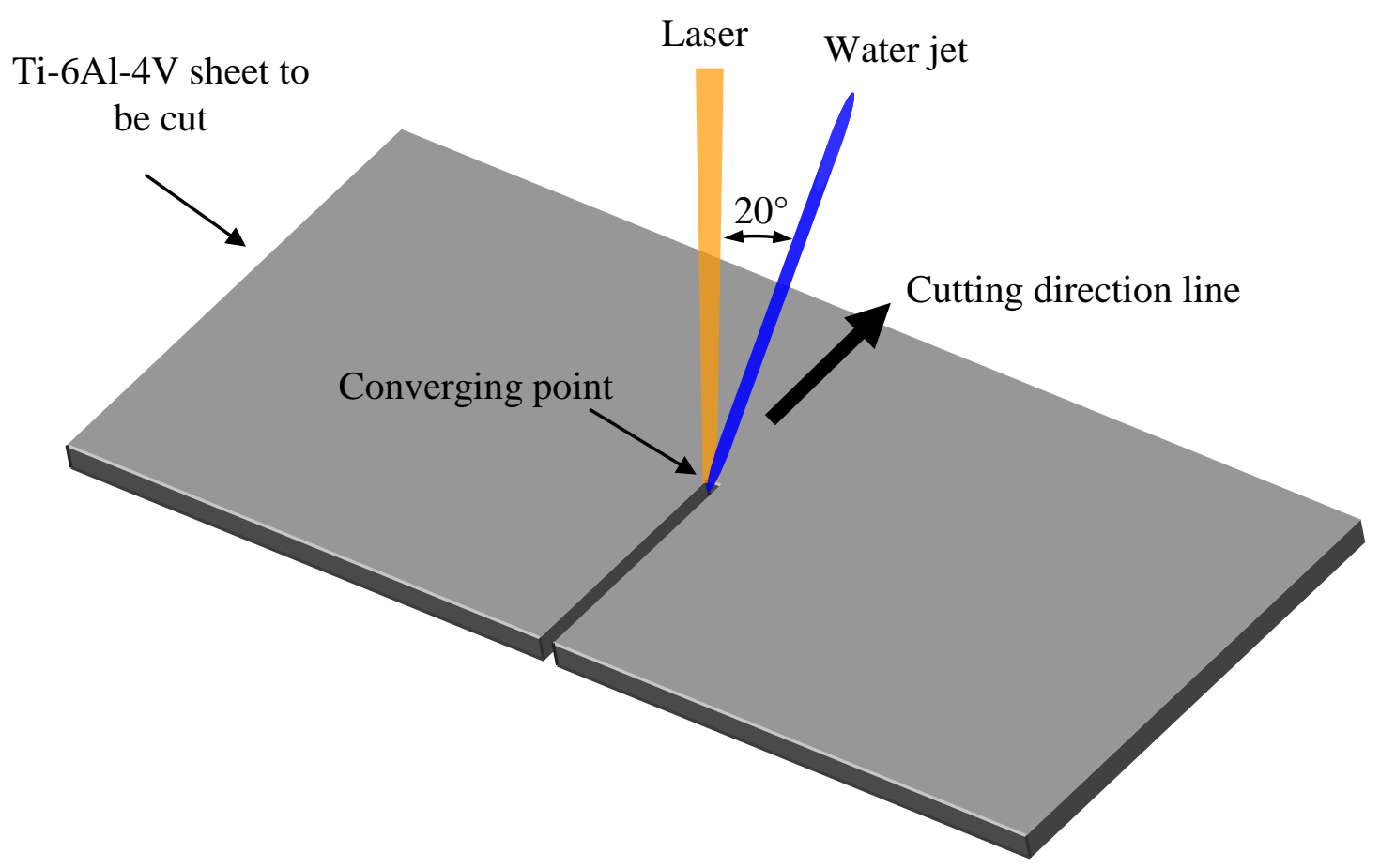


Fig 2 : Macroscopic view of a sample after cutting (speed $6 \mathrm{~m} \cdot \mathrm{min}^{-1}$ ) and zoom on the oxidized zone (x5)

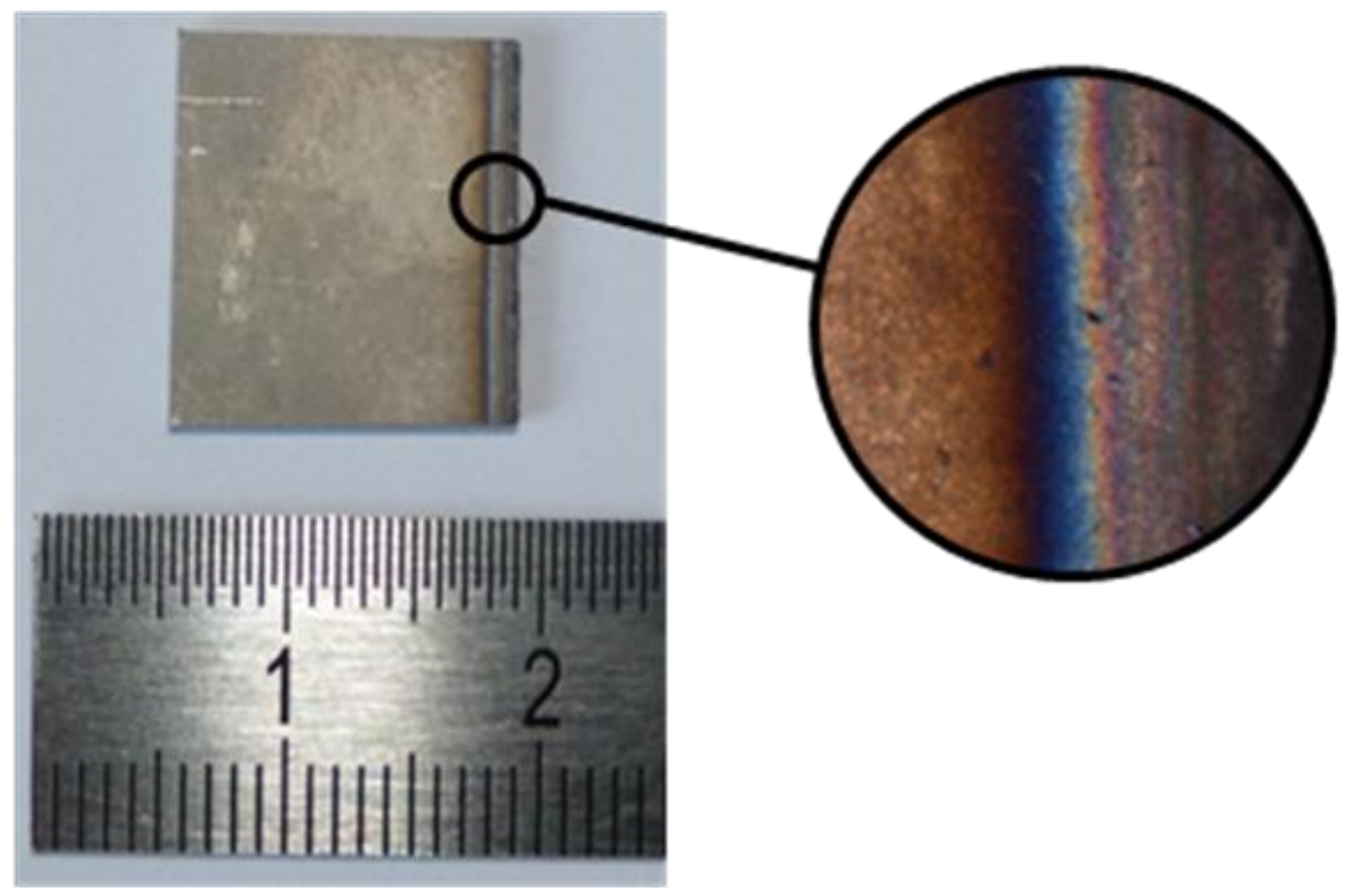


Fig 3 : Evolution of the width of the oxidized zone as function of the cutting speed.

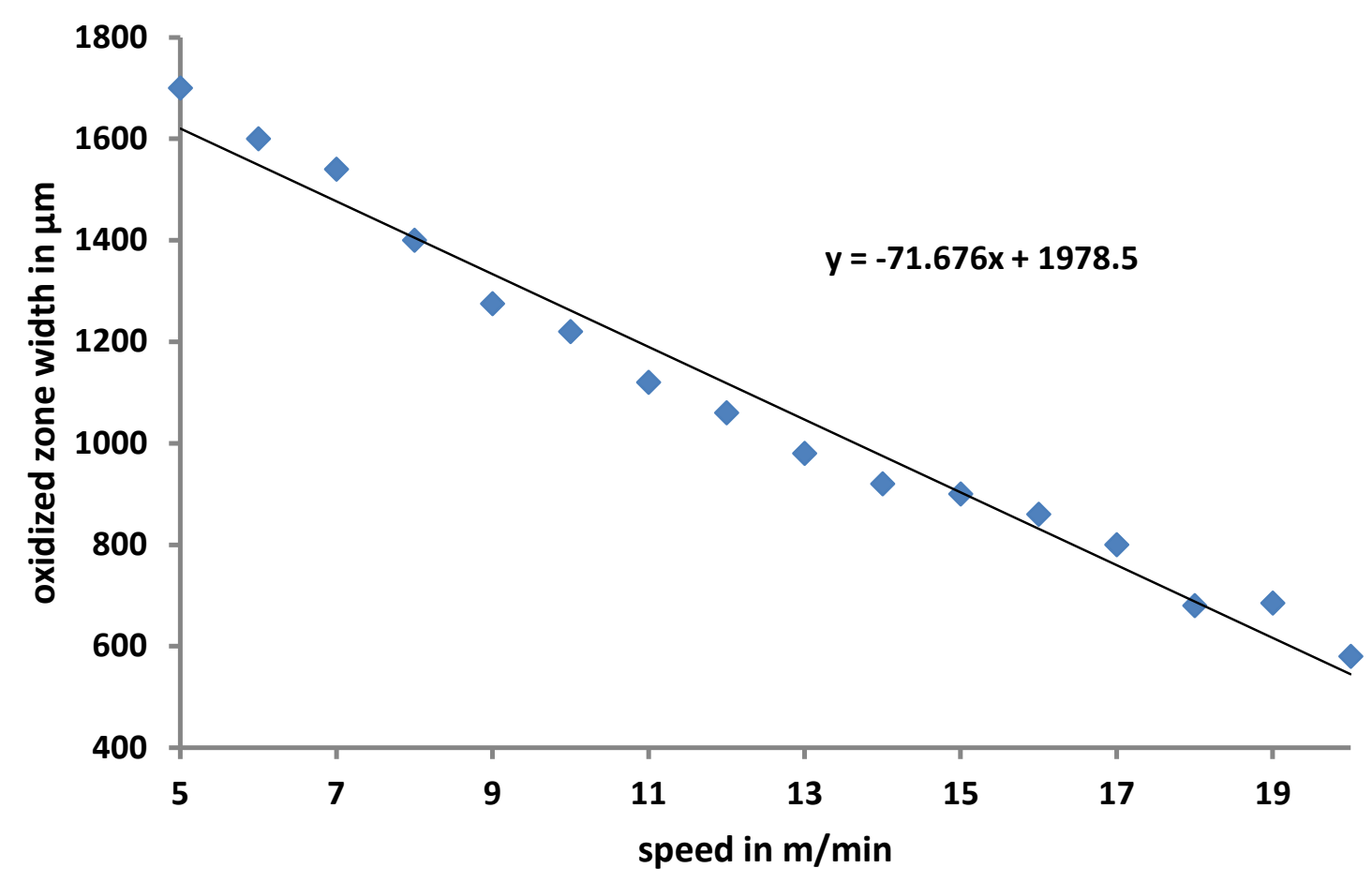


Fig 4 : Comparison between XRD patterns of oxidized zone and unaffected Ti-6Al-4V sample

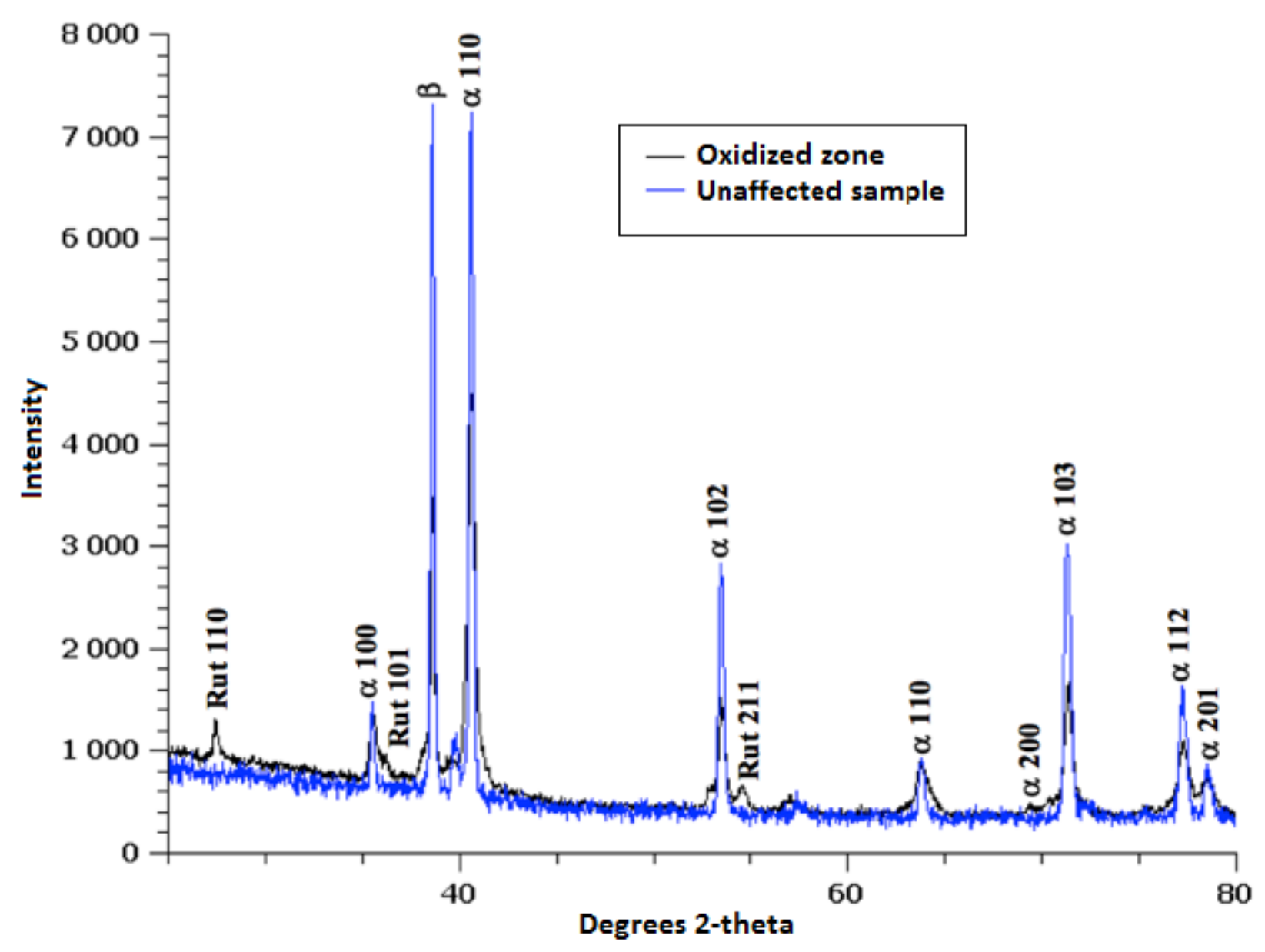


Fig 5 : Comparison between Raman spectrum of oxidized zone, Ti-6Al-4V raw material on the surface and powder.

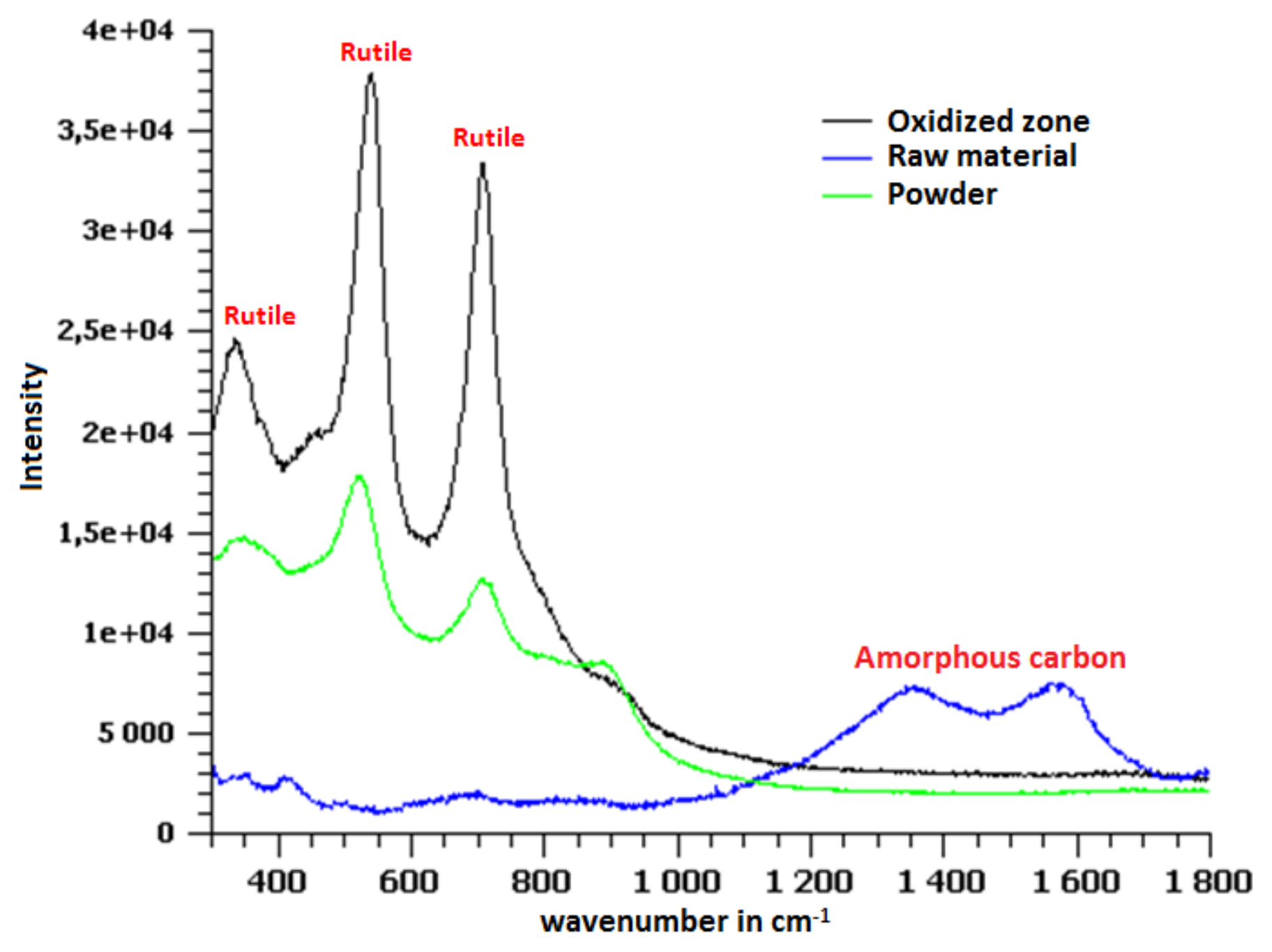


Fig.6 : SEM picture of macroscopic view of the rough edge at the opposite of the laser water jet entrance and focus on the edge: a. Band contrast, b. Phase map (blue as alpha and red as beta) and c. EBSD map

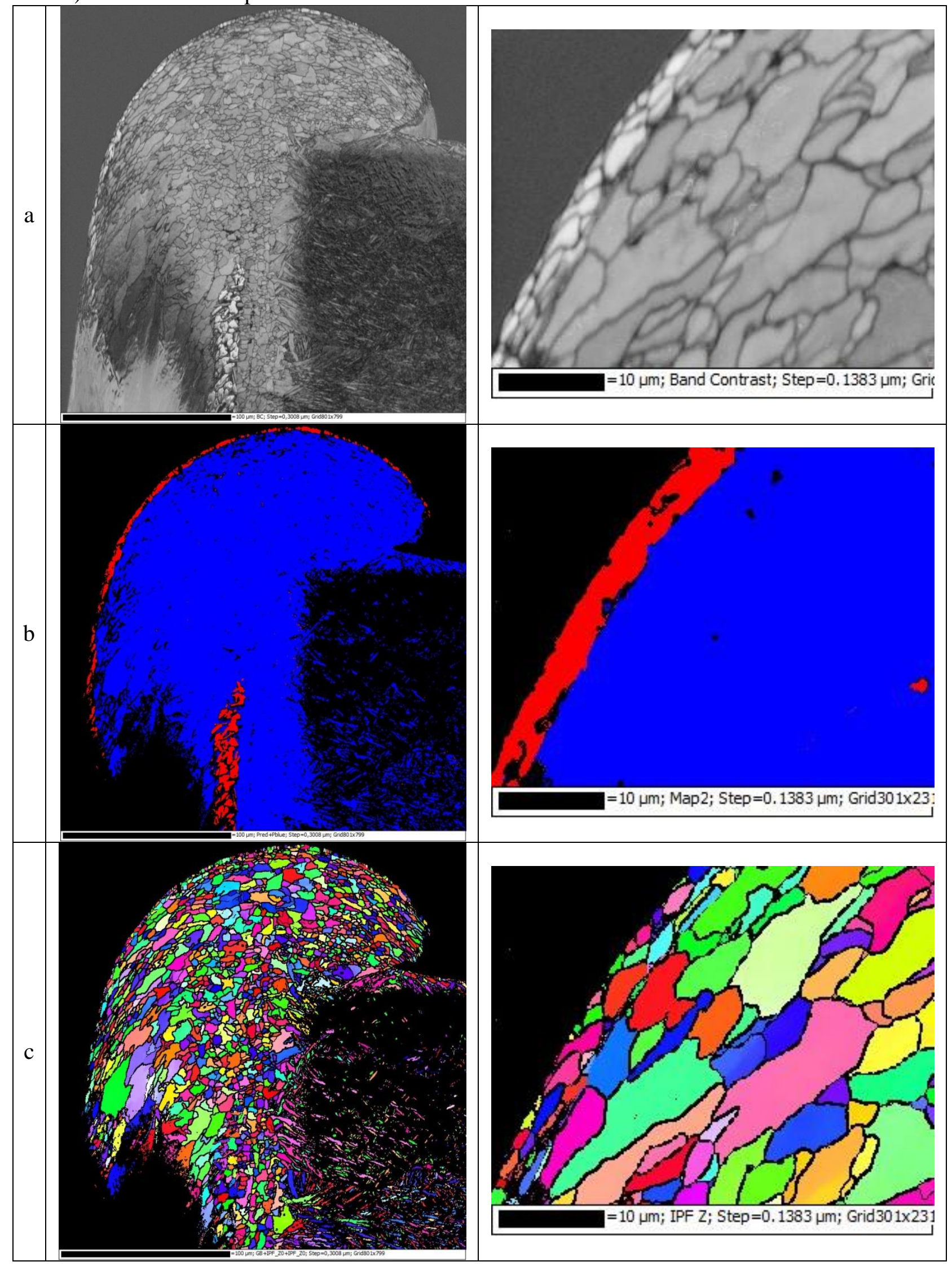


Fig. 7 : CCT diagram for Ti-6Al-4V extracted from Ref.[23]

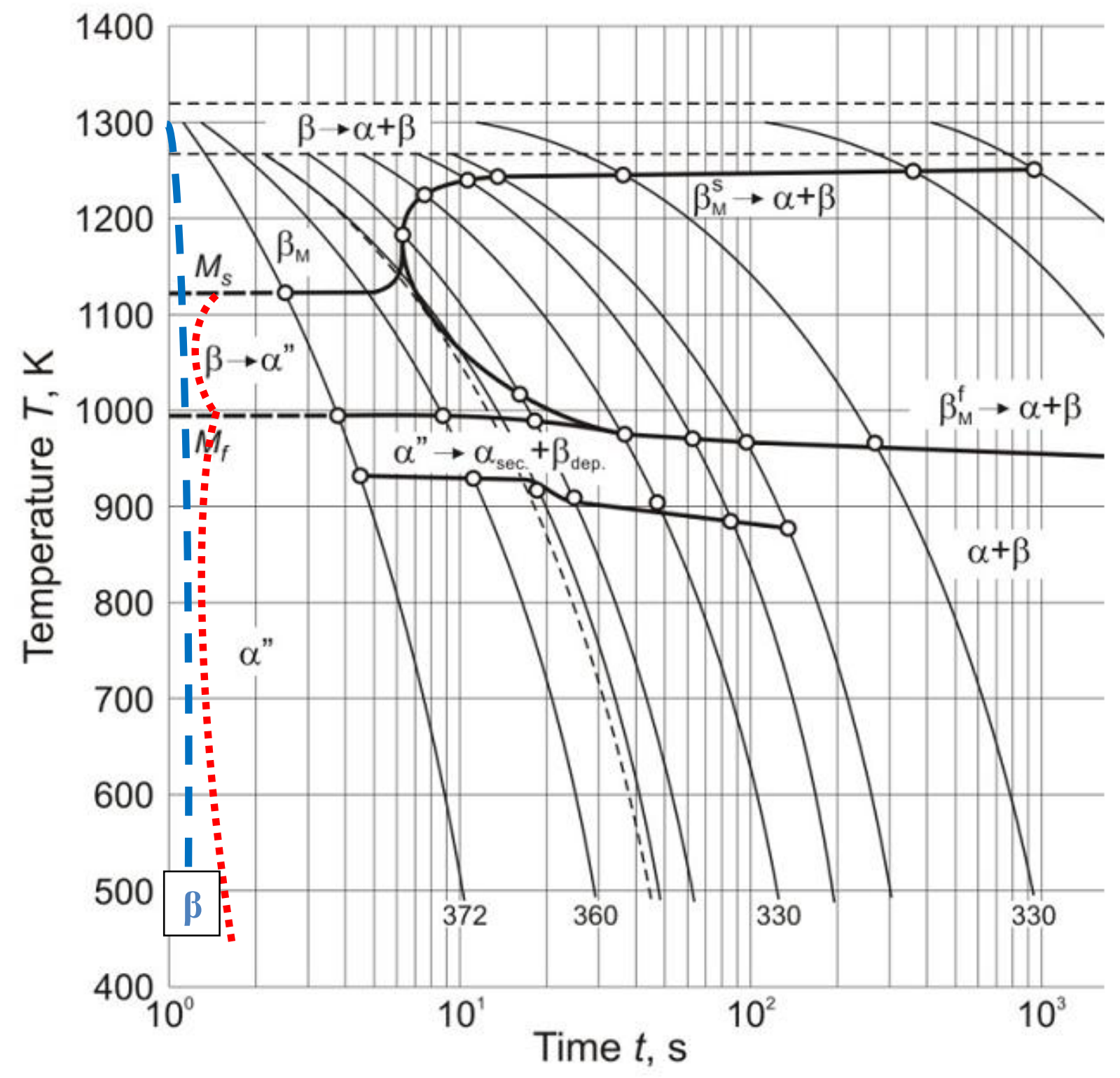


Fig.8 : Linear chemical analysis on the cross section across the beta phase skin with: a. SEM macroscopic picture and b. chemical results

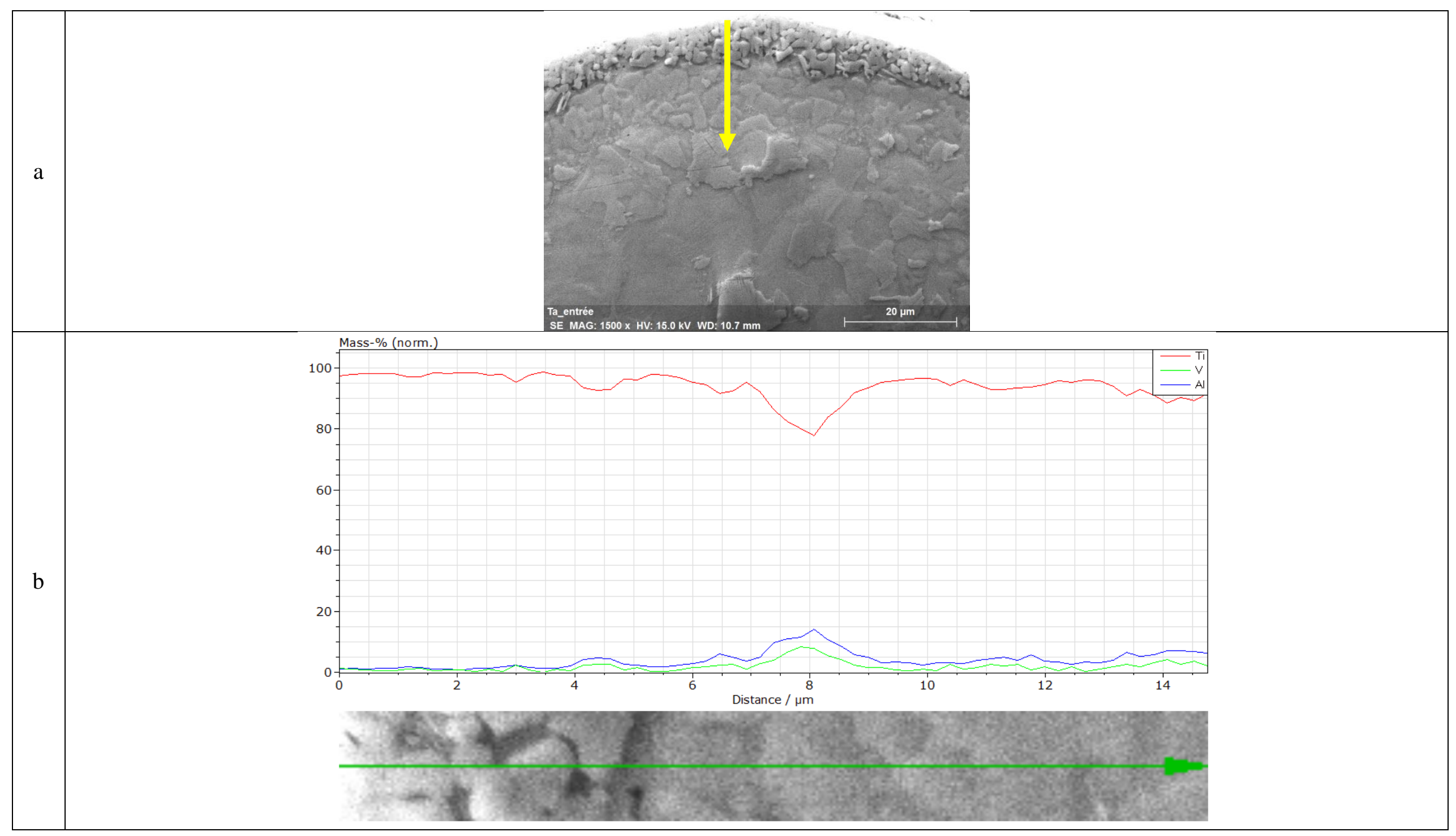


1
2
3
4
5
6
7
8
9 